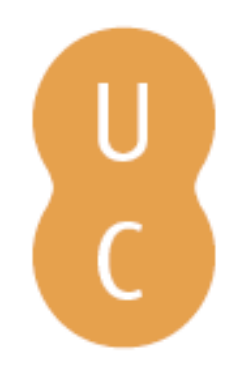

\title{
pommalina
}

\section{Culinária e etiqueta em Portugal nos anos 30: as propostas de Estela Brandão}

\author{
Autor(es): $\quad$ Braga, Isabel M. R. Mendes Drumond
}

Publicado por: Imprensa da Universidade de Coimbra; Annablume

URL

persistente: $\quad$ URI:http://hdl.handle.net/10316.2/39658

DOI: $\quad$ DOI:https://doi.org/10.14195/978-989-26-1191-4_29

Accessed : $\quad$ 26-Apr-2023 11:18:15

A navegação consulta e descarregamento dos títulos inseridos nas Bibliotecas Digitais UC Digitalis, UC Pombalina e UC Impactum, pressupõem a aceitação plena e sem reservas dos Termos e Condições de Uso destas Bibliotecas Digitais, disponíveis em https://digitalis.uc.pt/pt-pt/termos.

Conforme exposto nos referidos Termos e Condições de Uso, o descarregamento de títulos de acesso restrito requer uma licença válida de autorização devendo o utilizador aceder ao(s) documento(s) a partir de um endereço de IP da instituição detentora da supramencionada licença.

Ao utilizador é apenas permitido o descarregamento para uso pessoal, pelo que o emprego do(s) título(s) descarregado(s) para outro fim, designadamente comercial, carece de autorização do respetivo autor ou editor da obra.

Na medida em que todas as obras da UC Digitalis se encontram protegidas pelo Código do Direito de Autor e Direitos Conexos e demais legislação aplicável, toda a cópia, parcial ou total, deste documento, nos casos em que é legalmente admitida, deverá conter ou fazer-se acompanhar por este aviso. 


\title{
Culinária e Etiqueta em Portugal nos Anos 30: as Propostas de Estela Brandão Cooking \& Etiquette in Portugal in the Thirties: the proposals by Estela Brandão
}

\author{
Isabel M. R. Mendes Drumond Braga \\ Universidade de Lisboa, Faculdade de Letras e CIDEHUS-UE \\ isabeldrumondbraga@hotmail.com
}

REsumo: As propostas culinárias portuguesas dos anos 30 do século XX revelam uma significativa capacidade de adaptação às novas realidades económicas do período entre as duas guerras mundiais, ao mesmo tempo que se viram para públicos diferenciados, com destaque para os menos abastados e com fraca formação. É neste contexto que apareceram obras pensadas para ensinar a preparar refeições simples, económicas e variadas, a par de conselhos básicos relativos ao aproveitamento de restos, a truques para poupar, a par de regras de etiqueta e de um conjunto de preparações muito variadas relativas a questões que poderíamos definir como de economia doméstica em sentido lato, uma vez que abrangem matérias tão diferentes como tirar nódoas, lavar loiça, cuidar da criação, etc.

No âmbito deste texto, pretende estudar-se o contributo conservador de Estela Brandão, através da sua obra em três volumes intitulada Arte e Economia (19371940) e de uma outra cujo título é Regras de Bem Viver na Sociedade (1938), com vista a ensinar e preparar as jovens pouco conhecedoras das realidades domésticas. Esta abordagem será complementada com a comparação com outras publicações da época, designadamente alguns livros de receitas de Rosa Maria e de Branca Miraflor, autoras que na mesma época demonstraram preocupações semelhantes.

Palavras-chave: Culinária, Economia doméstica, Estela Brandão, Portugal, século XX.

Авstract: Portuguese culinary proposals of the thirties of the twentieth century show a significant ability to adapt to new economic realities of the period between the two world wars, also aiming at different audiences, especially the least wealthy and with little instruction. It is in this context that works designed to teach how to prepare simple, economic and varied meals appeared. These also gave some basic advice concerning the use of leftovers, and tips for saving money, along with etiquette rules and a set of extremely varied preparations for issues that could be defined as home economics in a broad sense, as they cover subjects as diverse as stain removers, dishwashing, feeding and tending to farmyard animals, etc.

Within the scope of this text, it is aimed to study the conservative contribution by Estela Brandão, by means of her work published in three volumes entitled Arte e Economia (1937-1940) and another entitled Regras para Bem Viver em Sociedade 
(1938), in order to teach and prepare the young girls who knew little about the domestic realities. This approach will be complemented with a comparison with other publications of the time, including some cookbooks by Rosa Maria and Branca Miraflor, authors who showed similar concerns in the same period.

Keywords: Cooking, Home Economics, Estela Brandão, Portugal, 20th Century.

\section{i. Contexto Político}

Em 1916, o governo liderado por Afonso Costa tomou a opção da entrada de Portugal na I Guerra Mundial, ao lado da Inglaterra, França, Itália, Bélgica, Rússia e outros países, contra a Alemanha, a Áustria e seus aliados. Foram várias as motivações para essa decisão: o Partido Democrático, que se achava no poder e que dominava a máquina eleitoral, conseguia congregar os Portugueses em torno de um projeto comum, tido como patriótico (logrou o apoio de um outro partido, o evolucionista, e os próprios monárquicos cessaram as tentativas restauracionistas); o regime republicano português conseguia uma maior aceitação por parte da Inglaterra, que nunca vira com agrado a proclamação da república (1910); Portugal demarcava claramente a sua posição em relação a Espanha, neutral e acusada por muitos de germanófila; e, finalmente, tentava defender as colónias africanas da cobiça da Alemanha.

Em 1917, tropas portuguesas, o chamado Corpo Expedicionário Português, formado pelo ministro da Guerra, general Norton de Matos, passaram a intervir no teatro de guerra europeu, enquanto outros contingentes foram defender Angola e Moçambique dos ataques alemães. A guerra trouxe a crise: aumento do custo de vida, escassez de géneros de primeira necessidade, fome, desemprego, agitações populares de rua, assaltos a lojas e greves. Portugal estava descontente com a participação num conflito que, pelo menos no teatro europeu, nada lhe dizia e tal em parte levou ao golpe de Estado liderado por Sidónio Pais, em dezembro de 1917. O novo líder, acusado por alguns de germanófilo, diminuiu o esforço de guerra de Portugal. A I Guerra Mundial terminou em Novembro de 1918 e o país viu-se reconhecido entre os vencedores, sendo confirmada a posse das suas colónias. Nos anos que se seguiram ao fim do conflito, Portugal continuou a viver as sequelas da guerra, com inflação, desvalorização da moeda, falência de bancos e empobrecimento generalizado ${ }^{1}$. A conjuntura era, consequentemente, bastante desfavorável do ponto de vista económico. E a situação não melhorou nos anos seguintes nem dentro nem fora de Portugal.

\footnotetext{
${ }^{1}$ Marques 1991a: 709-717; Martinez 2001: 135-319; Rosas 2009: 245-406.
} 
A grande crise económica que se seguiu a 1929 levou os Estados europeus ao desenvolvimento de uma mentalidade autárcica, entrincheirando-se nas suas fronteiras económicas, fechando-se a contactos com o exterior e aumentando as barreiras alfandegárias. Este nacionalismo económico fez reavivar velhos ódios e inimizades que se agudizaram com a subida ao poder na Alemanha de Hitler (1933) que, no seu livro Mein Kampf (1923), apresentara um programa claramente expansionista: vingar a derrota sofrida em 1918, criar uma "Grande Alemanha", constituída por todos os povos de sangue germânico e criar um "espaço vital" alemão, o que implicaria uma expansão em direção ao Leste.

Em outubro de 1936, constituiu-se o eixo Roma-Berlim. No mês seguinte, foi criado o Pacto Anti-Komintern, a que aderiu o Japão. A solidariedade entre os dois regimes totalitários europeus manifestou-se muito claramente nas visitas de Mussolini a Berlim (setembro de 1937) e de Hitler a Roma (maio de 1938). De julho de 1936 a março de 1939, deu-se a Guerra Civil de Espanha, o primeiro teatro em que se defrontaram os blocos mais tarde em oposição na II Guerra Mundial, além de se terem testado técnicas e materiais bélicos.

A conferência de Munique, realizada a 29 e 30 de setembro de 1938, reuniu Hitler, Mussolini e os primeiros-ministros da Inglaterra e da França. Estes dois cederam às exigências alemãs. A Checoslováquia deixara de existir. À referida conferência de Munique seguiram-se acordos bilaterais entre a Alemanha e a Inglaterra e a Alemanha e a França, reafirmando-se as relações pacíficas entre esses Estados. Acreditou-se que assim se evitara a guerra. Mas, em março de 1939, faltando ao que cumprira na referida conferência, Hitler mandou invadir Praga e constituiu o protetorado da Boémia-Morávia. No mês seguinte, foi a vez de Mussolini anexar a Albânia. A 1 de setembro, Hitler invadiu a Polónia. Dois dias depois, a França e a Inglaterra declararam guerra à Alemanha. Tinha começado a II Guerra Mundial (1939-1945) que opôs os chamados aliados (Inglaterra, França, Estados Unidos da América, União das Repúblicas Socialistas Soviéticas e outros) às denominadas potências do eixo (Alemanha, Itália e Japão)².

Em Portugal, o Estado Novo manteve a aliança com a Inglaterra, mas também estreitou relações com países onde vigoravam regimes de tipo fascista, como por exemplo a Itália e a Alemanha. No caso da Espanha, Salazar apoiou o levantamento militar de 1936 (feito contra um governo de coligação socialista e comunista), que conduziu à Guerra Civil e à vitória final do general Franco, ou seja, à institucionalização de um regime aparentado

\footnotetext{
${ }^{2}$ Sobre a II Guerra Mundial, a bibliografia é muito vasta. Cf., de entre outros, por exemplo, Parker 1989; Gibert 2009.
} 
com o de Portugal. A atitude de Salazar foi de neutralidade pois, embora ideologicamente se achasse próximo da Alemanha e da Itália, não pretendia romper a duradoura ligação de Portugal a Inglaterra. Ainda assim, havia em Portugal partidários quer da Alemanha quer da Inglaterra ${ }^{3}$. O país não era autossuficiente em termos alimentares, dependia do abastecimento exterior de muitos géneros e a política agrícola do Estado Novo não conseguiu revelar-se eficaz, apesar de, exatamente nos anos 30, a chamada "Campanha do Trigo" ter tido inicialmente resultados promissores, com o aumento da área de produção, que terminaram na época do início da II Guerra Mundial. Ou seja, o conflito armado apenas tornou mais evidentes as vulnerabilidades estruturais da economia portuguesa ${ }^{4}$.

\section{As Propostas Culinárias}

No período entre as duas Guerras Mundiais, concretamente na década de 30, surgiram vários livros de receitas destinados a públicos menos exigentes, isto é, pessoas menos abastadas e com fraca formação. A I Guerra Mundial implicou uma simplificação dietética, aliada à escassez dos géneros alimentares e ao consequente racionamento, o que levou a alterações nos hábitos gastronómicos, com a diminuição de pratos por refeição, pondo fim à longa herança de sumptuosas refeições quotidianas entre os abastados. A II Guerra Mundial consolidou esta realidade ${ }^{5}$. O mesmo aconteceu na Itália de Mussolini ${ }^{6}$ e em Espanha, um espaço que conheceu uma situação mais agravada em resultado da Guerra Civil 7 . Neste contexto, e em Portugal, destaquem-se os casos das autoras Estela Brandão, Rosa Maria e Branca Miraflor, cujas obras, no entanto, não se destinaram exatamente ao mesmo tipo de leitoras.

Estela Ramalho Nunes de Sá Brandão (1889-1960) cursou Belas Artes, estudou piano no Conservatório de Música do Porto e exerceu funções docentes em línguas e em música. Foi autora de obras para crianças e colaborou em jornais do Norte de Portugal, designadamente Correio do Minho (Braga) e Estrela do Minho (Vila Nova de Famalicão), usando o pseudónimo Simone. No primeiro, assinou uma coluna intitulada "Para vós, minhas Senhoras" que,

3 Sobre a posição política de Salazar face à II Guerra Mundial, cf. Meneses 2010: 249-357.

${ }^{4}$ Nunes, Brito 1992: 319-321; Rosas 1994: 322-327.

${ }^{5}$ Sobre esta realidade, cf. Marques 1991b: 617-626.

${ }^{6}$ Sobre a Itália de Mussolini, nos anos 30, e em concreto sobre o pouco entusiasmo a nível local pelo fascismo, cf. Corner 2015:221-250, passim.

7 Sobre os problemas da fome durante a Guerra Civil Espanhola, cf., de entre outros, Romero Samper 2013: 159-190. Não obstante, a propaganda política recorria a turismo político, investindo na hospitalidade dos visitantes, os quais eram controlados politicamente. Sobre esta matéria, cf. García 2006: 287-308. 
posteriormente, reuniu em livro sob o mesmo título, publicado em $1938^{8}$. Nestas crónicas sobre vários assuntos, em particular acerca das funções das mulheres no lar, demonstrou de forma cabal o seu posicionamento conservador, como já foi salientado por Maria Teresa Santos ${ }^{9}$. Escreveu também um manual de etiqueta, intitulado Regras de Bem Viver na Sociedade, publicado igualmente em 1938. A obra, dividida em 24 capítulos, remeteu várias vezes para o seu livro mais conhecido Arte e Economia, designadamente quando referiu ceias e refeições cerimoniosas. No prólogo, esclareceu os propósitos que nortearam a publicação: "dando publicidade a este livrinho, pensei ser útil àqueles que, por um capricho da sorte, foram colocados numa esfera social superior àquela onde foram nascidos e criados. Hoje em dia é isto um caso vulgar. E daí o verem-se às vezes em embaraços, para proceder como manda a etiqueta e as praxes sociais" ${ }^{10}$. Ou seja, a autora fez alusão ao fenómeno cíclico de ascensão social, que sempre deu origem a públicos cujo poder económico aumentou mas que necessitavam de ser educados, pois não tinham tido uma formação de base própria do meio ao qual acabavam de ascender ${ }^{11}$.

A obra mais conhecida de Estela Brandão, publicada em 1934 e com segunda edição aumentada entre 1937 e 1940, intitulou-se Arte e Economia. Foi dedicada à neta, Maria de Lourdes Brandão d'Almeida, e dividida em três volumes. O primeiro abordou a culinária, o segundo as receções, ceias, chás, doces e licores, continuando a fornecer receitas, e o terceiro uma enciclopédia caseira além de dois tratados sobre criação de aves e coelhos. No prólogo, pediu a benevolência das leitoras e apresentou a obra, finalizando: "parece-me ser assim útil às meninas inexperientes, que se vejam em dificuldades na sua vida caseira, desejando-lhes que encontrem no meu trabalho um conselho amigo e poderoso auxiliar" ${ }^{12}$.

Em Arte e Economia, Estela Brandão começou por fornecer ementas para 30 dias, coligidas a partir de receituários que não identificou, das cozinhas portuguesa e francesa. Afirmou que as receitas constituíam fórmulas garantidas, todas experimentadas, tendo dado ótimo resultado e tendo agradado. Explicitou ainda que "nenhuma das minhas ementas tem bacalhau. É um alimento pesado, mas que na província tem que empregar-se, pela falta de recursos"13. As vinte receitas de bacalhau apareceram à parte, no final do livro. Sobre estas entendeu que eram "das que me parecem melhores e mais

\footnotetext{
${ }^{8}$ Sobre alguns elementos biográficos de Estela Brandão, cf. Oliveira 1981: 168; Santos 2005: 324.

${ }^{9}$ Santos 2005: 324.

10 Brandão 1938a: 5.

11 Sobre estas matérias, cf. Visser 1991: 69-78 passim; Braga 2004: 13-14.

12 Brandão 1937: n. num.

13 Brandão 1937: 9.
} 
delicadas" ${ }^{14}$. Estela Brandão tornou, desde logo, muito claro que era urbana mas que escrevia para mulheres das cidades e das zonas rurais.

No início do volume dedicado à culinária, considerou que "as refeições abundantes e pesadas entorpecem o espírito, amolentam a vontade e arruínam a saúde e a bolsa" ${ }^{15}$. Deteve-se também no que entendeu ser uma gestão racional dos recursos das famílias, ao escrever: "a economia é para todos útil, mormente àqueles cujos meios de fortuna não abundam. Porém, deve ser uma economia inteligente que abrangerá em último lugar a mesa, pois a alimentação sã e abundante representa uma grande economia: no médico, farmácia e nas aflições que nos causa os filhos ou o marido doente ou enfraquecidos" ${ }^{16}$. Neste sentido, era imprescindível que as donas de casa fossem dotadas de um conjunto de qualidades, a saber: paciência, tenacidade, bom humor e atitudes com vista a facilitar a economia ${ }^{17}$, matérias que irá desenvolver ao longo de algumas páginas. Apesar de tudo, pressupôs, em vários momentos, que se estava a dirigir a mulheres em cujas casas havia uma ou duas criadas, mas que com estas dividiam tarefas domésticas ${ }^{18}$. Por exemplo, no terceiro volume apresentou um manual para a criada de sala e um outro para a de cozinha e considerou: "hoje em dia, com a carestia da vida, rara é a casa que pode ter mais que duas criadas, a não ser que as pessoas da casa sejam em número elevado, que careçam de muito pessoal para a boa organização do ménage" [...] havendo como é uso, duas criadas, a de sala levantar-se-á às 7 $1 / 2$ no inverno e às 7 no verão" ${ }^{19}$. Ou seja, dirige-se a um público feminino alfabetizado com meios mais do que escassos mas menos do que abundantes.

Ao longo da obra, Estela Brandão insistiu em questões básicas de pontualidade, de higiene e de elegância doméstica. Sugeriu a aquisição de um relógio para a cozinha, a comunicação de instruções precisas por parte da dona de casa à criada acerca dos horários das refeições, para os preparados não chegarem frios à mesa e um conjunto de medidas que deveriam ser implementadas visando a boa ordem e limpeza quer das instalações onde eram preparados e servidos os alimentos quer dos utensílios, sem esquecer os panos e os aventais ${ }^{20}$. A elegância da mesa das refeições e da sala onde eram tomadas foram assuntos abordados em vários momentos ${ }^{21}$. Por exemplo: "as toalhas e guardanapos quanto possível da cor das flores ou, pelo menos,

\footnotetext{
${ }^{14}$ Brandão 1937: 9.

${ }^{15}$ Brandão 1937: 10

16 Brandão 1937: 14

${ }^{17}$ Brandão 1937: 10-21.

${ }^{18}$ Sobre esta realidade em outros espaços, cf. Capatti, Montanari 2002: 301.

${ }^{19}$ Brandão 1940: 9.

${ }^{20}$ Sobre a organização e a limpeza do espaço doméstico, cf. Silva 2008: 108-121.

${ }^{21}$ Este tipo de preocupações também era visível nas revistas femininas. Cf., por exemplo, Braga 2007: 216-217.
} 
barras da mesma cor em fundo branco. Para jantar é sempre mais elegante e belo a toalha branca, mas no campo e na praia dá um ar alegre e vistoso essas toalhas bordadas com barras garridas" ${ }^{22}$ ou "a comida mal apresentada, perde metade do seu sabor" ${ }^{23}$. Era a tradicional aliança entre valor gastronómico dos pratos e apresentação dos mesmos ${ }^{24}$.
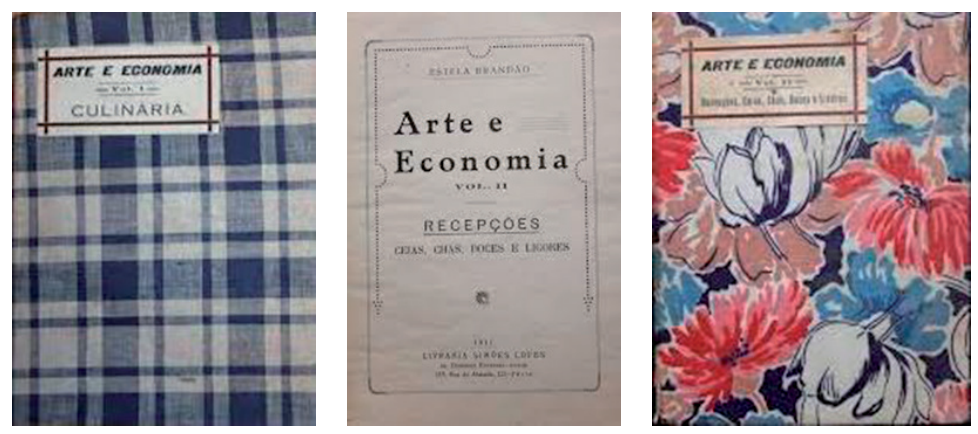

Figs 1, 2, 3 - Duas capas e um frontispício da obra de Estela Brandão, Arte e Economia.

O receituário de cozinha apresentado no primeiro volume compreendeu 30 ementas de almoço e outras tantas de jantar, num total de 382 preparados. Genericamente, pode afirmar-se que as refeições foram constituídas por entrada, apenas nos almoços, dois pratos e sobremesa, embora em alguns casos o segundo prato não fosse mais do que o acompanhamento do primeiro. $\mathrm{O}$ jantar foi sempre objeto de mais atenções, apresentando, em alguns dias, duas sobremesas, uma de doce outra de fruta. Realce para o facto de as receitas de entradas terem sido fornecidas à parte e depois de esclarecimentos básicos prévios: "em quase todos os almoços é bonito servir as entradas próprias, que constituem um belo aperitivo. As entradas clássicas, tais como manteiga, rabanetes, azeitonas, camarões, sardinhas de lata, fiambre, paio, foie-gras, tudo isto não tem preparação especial [...] fora essas entradas há muitas outras que se preparam com antecedência e que se podem classificar em entradas quentes e frias" ${ }^{25}$. Das primeiras forneceu 17 e das segundas 10. A sobremesa também mereceu comentários: "não é dispensável, faz parte do alimento, pois contém na sua maior parte ovos, leite, substâncias muito nutritivas, permitindo ficar com o estômago leve e trabalhar logo após a refeição sem prejuízo para a saúde” ${ }^{26}$.

\footnotetext{
${ }^{22}$ Brandão 1937: 19.

${ }^{23}$ Brandão 1940: 27.

${ }^{24}$ Capatti, Montanari 2002: 228.

${ }^{25}$ Brandão 1937: 99.

${ }^{26}$ Brandão 1937: 10.
} 
Nas receitas não se verificou a separação entre ingredientes e modos de preparação e nem sempre se indicaram as quantidades de todos os géneros, nem tão pouco os tempos de preparação e de cozedura, aspetos que constituem marcas de um arcaísmo significativo, pois são características que se podem encontrar nos livros de cozinha anteriores ao século XIX. Se bem que Estela Brandão, quando indicou quantidades, o tenha feito utilizando o sistema métrico-decimal, o que não é para estranhar uma vez que estava em vigor desde 1852, numa receita, "doce de viúvas", chegou a referir as libras ${ }^{27}$. Como se assumiu como compiladora e não como autora, torna-se evidente que possuía, como todas as pessoas que cozinham, receitas de várias épocas e proveniências. Por outro lado, em alguns casos, o receituário indicou que deveria ser utilizada certa massa ou determinado molho mas não remeteu para a seção da obra onde os mesmos se encontravam. Por exemplo, na receita de "couve-flor alourada", podem ver-se algumas destas questões: "Coze-se a couve-flor em água temperada de sal. Faz-se um molho branco com leite, farinha e manteiga, Unta-se um prato de ir ao forno, com manteiga. Escorrese a couve-flor da água, parte-se em bocadinhos e mistura-se no molho, que também leva pimenta, e uma ou duas colheres de queijo ralado. Polvilha-se esta massa, depois de estar no prato de ir ao forno, com queijo e pão ralado, regando-se com um pouco de manteiga e leva-se ao forno para tostar" ${ }^{28}$.

Os ingredientes utilizados foram muito variados e no âmbito deste texto não pretendemos fazer uma análise exaustiva dessa matéria. Contudo, queremos salientar que não raras vezes se referiu a conhaque, kirsch e rum, entre as bebidas, e a ingredientes eventualmente considerados mais mimosos e pouco comuns como os palitos a la reine, cuja receita forneceu, e os champignons, que nunca traduziu. Apesar de referir que compilara receitas portuguesas e francesas, alguma influência italiana também se fez sentir, nem que tenha sido por via indireta, pois integrou preparados com aletria e macarrão, sem esquecer pratos de risotto. Em sentido oposto, importa salientar a presença de diversos pratos em que não se identificaram as espécies de peixe e de carne e em que tais géneros foram utilizados picados, a par de receitas com as partes menos nobres das carnes, designadamente dobrada, fígado, línguas, mãos, miolos e rins. Ainda neste âmbito, realce para as de aproveitamentos, tais como bolo de peixe ou roupa velha de carne ${ }^{29}$.

No índice dividiu as receitas em 22 rubricas embora sem qualquer precisão: entradas quentes, entradas frias, sopas, molhos, aves, pato, ovos, caça, massas,

${ }^{27}$ Brandão 1937: 51.

${ }^{28}$ Brandão 1937: 26.

${ }^{29}$ Brandão 1937: 35, 56. Sobre a questão dos aproveitamentos, cf. Braga, 2007: 221; Braga, 2008: 117-141; Braga 2012: 201-226 e Vaquinhas, Guimarães 2011: 194-221. Para o espaço italiano, cf., por exemplo, Mafai 2008: 99-100. 
crepes, bacalhau, peixes, legumes, batatas, arroz e massas, macarrão, miúdos de vaca, salsicharia, carnes, sobremesas várias, pudins e cremes. Esta opção, aliada, em alguns casos, à maneira pouca clara de escrever - não obstante ter sido autora de um Manual Prático da Arte de Redigir, publicado em 1957 - e à própria arrumação da obra, vem demonstrar estarmos perante uma pessoa muito pouco organizada, uma das características que começou por enaltecer nas donas de casa.

No segundo volume de Arte e Economia, a autora dedicou-se às receções familiares, íntimas e cerimoniosas, definindo cada categoria e fornecendo receitas, num total de 278, que entendeu adequadas para esses momentos. Mais uma vez, o aparecimento das considerações e dos vários assuntos não foi o mais metódico. Referiu-se ao chá, café, chocolate e chocolate com ovos e às maneiras de preparar estas bebidas, em seguida forneceu uma lista de utensílios para fazer "toda a qualidade de doces", passou para o açúcar em calda, para os pontos de açúcar e para os glacés ${ }^{30}$. Posteriormente, apresentou sugestões de receitas para três merendas íntimas, três chás íntimos e 10 chás cerimoniosos. Seguiu-se uma secção sobre a ceia de Natal à moda do Minho, outra sobre a ceia de Natal, presumivelmente do resto do país, uma outra para o dia 31 de dezembro. Fez marcha atrás e regressou ao lunch do dia de Natal para saltar em seguida para o do dia 1 de janeiro.

Enalteceu a maneira de servir o chá, naturalmente pela dona da casa ou por uma menina da família, o qual deveria ser acompanhado por torradas ou pãezinhos, bolos secos, doces de ovos e, por fim, bombons, amêndoas, rebuçados, etc. ${ }^{31}$, numa mesa bonita e bem decorada. Mas foram as ceias natalícias que mais a terão fascinado: "as ceias de Natal têm, em cada país, seus usos e costumes. Em Portugal, variam um pouco de Norte a Sul. No Norte, ainda se conserva a tradição (aliás bem interessante e comovente) de reunir toda a família no dia 24 , para a clássica ceia de Natal, que é servida das 8 para as 9 da noite" ${ }^{32}$.

Nas considerações que publicou teve preocupações de adequação da ingestão dos alimentos às épocas do ano. Por exemplo, entendeu que, "no inverno, o chocolate é muito indicado, não só por ser um bom alimento, agradável ao paladar, como tem a vantagem de aquecer e confortar. Sempre que ele se sirva, deve fazer-se acompanhar com torradas e um copo de água fria, evitando servir nessa ocasião iguarias de carne ou conserva" ${ }^{33}$ ou ainda

\footnotetext{
${ }^{30}$ Brandão 1939: 14-20.

31 Brandão 1939: 14.

32 Brandão 1939: 55.

33 Brandão 1939: 12
} 
que "não deve porém faltar nestas ocasiões frutas frescas no verão, compotas, nozes e figos secos no inverno" ${ }^{34}$.

As receitas apresentadas neste volume foram divididas em várias secções: pãezinhos diversos, neles incluindo scones e torradas com mel e nozes; doces diversos, uma miscelânea tão abrangente que contém aletria, arroz doce, cremes, crepes, frutas assadas e cristalizadas, marrons glacés, massapães, nuvens, ovos-moles, pastéis, pudins, queques, rabanadas, sonhos, tortas, de entre outros preparados; e ainda as secções de bolos, incluindo um de noiva; biscoitos, rebuçados, compotas, sorvetes, carapinhadas, bebidas geladas, bebidas quentes e, finalmente, licores.

No último volume, além dos referidos manuais para as criadas de sala e para as de cozinha, Estela Brandão incluiu uma rubrica intitulada "O que todas as donas de casa devem saber". Trata-se de uma mini enciclopédia organizada por ordem alfabética e com informações diversificadas: conselhos e remédios para resolver problemas de saúde (por exemplo aftas, anginas, desmaios, eczema, enjoos, enxaquecas, dores reumáticas, insónias e queimaduras), e de higiene do lar (limpar armas, chapéus, joias, nódoas, objetos de cobre e vidros, evitar a oxidação de metais e exterminar baratas, formigas, pulgas e ratos), conservar alimentos (azeitonas, evitar o ranço do azeite, eliminá-lo da manteiga) e outros bens, tais como peles; manipular preparados para obter cremes de beleza e para a barba ou ainda para evitar a queda de cabelo e a caspa, ou eliminar as rugas e os pelos ou extirpar os calos. A obra terminou com dois manuais acerca da criação de aves e de coelhos, com informações sobre as raças e as formas de as escolher, além de referências às doenças dos animais e às formas de atuar ${ }^{35}$. Ou seja, sendo uma mulher urbana não descurou a presença de casas citadinas com quintais onde se criavam espécies de pelo e de pena - pensemos no que chegou a ser protagonizado por Maria de Jesus Caetano Freire, a governanta de Salazar, que criou galinhas e coelhos nos pátios e jardins das residências particulares e oficiais do presidente do Conselho ${ }^{36}-\mathrm{e}$, naturalmente, as casas rurais habitadas por famílias cujas mulheres teriam interesse em informações sobre criação de galinhas e de coelhos.

Arte e Economia é, como o título indica, mais do que um livro de culinária. Aparentemente, consistiu numa miscelânea de assuntos díspares, mas que não eram assim entendidos nem no passado nem na época em que escreveu. Culinária, cosmética, farmacopeia e todo um conjunto de receitas para limpar e cuidar de produtos domésticos eram matérias que tinham como palco as

\footnotetext{
${ }^{34}$ Brandão 1939: 13.

${ }^{35}$ Brandão 1940.

${ }^{36}$ Vieira 2010: 49-50, 69.
} 
cozinhas das casas, e que se produziam a partir das heranças de conhecimentos de alimentação e saúde antigos, elaborados e reelaborados de acordo com as práticas e a integração de novos produtos. A união destas matérias era então uma realidade, pelos produtos, pelas técnicas e pelos locais de produção utilizados, quase sempre os mesmos ou com variantes pouco acentuadas.

Vejamos de que modo Estela Brandão se aproximou ou se afastou de autoras suas contemporâneas que visaram propósitos semelhantes, designadamente de Rosa Maria e de Branca Miraflor. A primeira é uma figura de quem nada se sabe, publicou diversos livros de cozinha, todos eles pautados pela ideia base de permitir às donas de casa realizar pratos económicos. A obra de maior sucesso foi $A$ Cosinheira das Cosinheiras, com 30 edições até 1982. Desconhece-se a data da primeira edição. A autora pretendeu aliar higiene, ideias sobre nutrição, sobriedade alimentar, saúde, receitas práticas e economia. Dirigida às donas de casa, visava facilitar as tarefas daquelas no que à alimentação familiar se referia. Rosa Maria teve em conta as necessidades calóricas das pessoas de acordo com a idade, a atividade física e as estações do ano, caracterizou alimentos e propôs regimes específicos para diabéticos, artríticos e ainda para os doentes de estômago, fígado e rins. Antes de passar às receitas, apresentadas por ordem alfabética, primeiro os salgados e depois os doces, ainda escreveu um capítulo acerca da necessidade de cozinhar os alimentos. Em certos momentos não faltaram considerações de teor moral. Por exemplo, ao referir-se ao vinho, explicitou: "do abuso do vinho têm resultado terríveis enfermidades, como a delirium tremens, a loucura, doenças de fígado, etc. e não menor número de desordens e desgraças de ordem moral, que têm levado muitos ao degredo, à penitenciária e ao patíbulo" ${ }^{37}$.

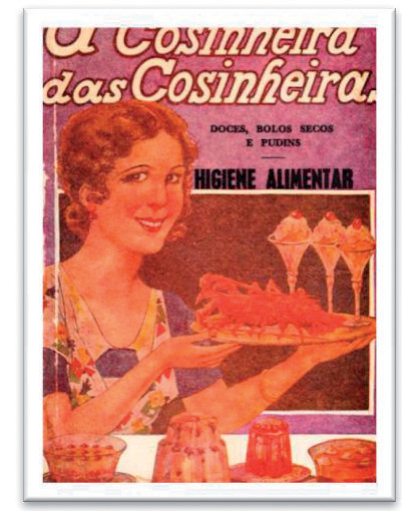

Fig. 4 - Capa da obra de Rosa Maria, A Cosinheira das Cosinheiras.

\footnotetext{
${ }^{37}$ Maria 1950: n. num.
} 
As dificuldades económicas e a necessidade de simplificar as refeições levaram à elaboração de menus simples e baratos, divulgados em livros de baixo custo, vendidos a $1 \$ 00$. Rosa Maria, no prefácio de um deles, Como se Almoça por 1\$50: 100 Almoços Diferentes, a isso mesmo se referiu, em 1933, data da primeira edição $0^{38}$. O mesmo aconteceu na obra Como se Janta por $3 \$ 00$. 100 Jantares Diferentes, publicada igualmente em $1933^{39}$. Ambos os livros conheceram três saídas até 1936 . O primeiro composto por 40 páginas, o segundo por 52 . Foram impressos em papel de má qualidade, com caracteres pequenos e sem índices. As receitas apresentadas eram naturalmente simples e económicas, sendo de destacar que entre elas não se contaram sobremesas, entendidas como um luxo, e que aparecem sempre os preços dos géneros, tendo em conta o mercado de Lisboa.
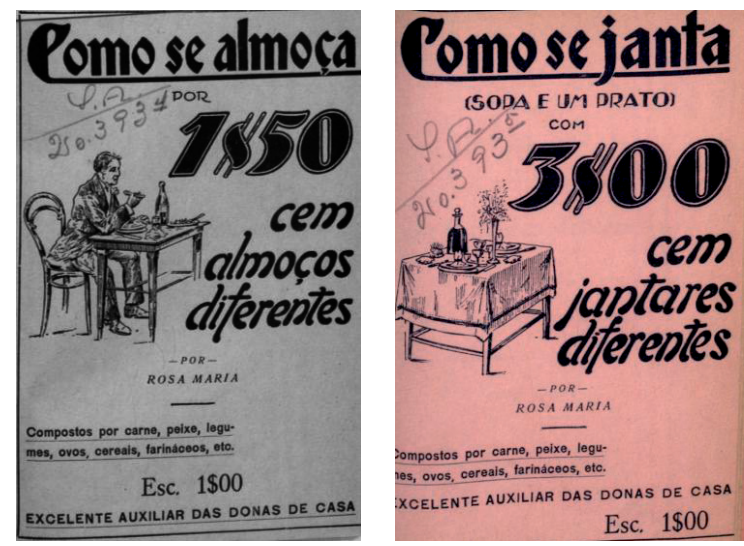

Figs 5 e 6 - Capas de duas obras de Rosa Maria

Rosa Maria explicitou, numa nota de abertura dirigida às leitoras, que: "ao elaborar estes menus económicos, tive em mira facilitar-vos, perante a escassez de recursos, uma série de almoços práticos e variados sem que com eles tenham que gastar mais do que o orçamento, porém estes almoços quando cozinhados em conjunto (para duas ou três pessoas) devem sair mais económicos, podendo por isso, aumentar as quantidades nutritivas, tais como manteiga, azeite, carne, ovos, etc. [...] não orçamentei vários temperos, tais como salsa, pimenta, noz-moscada, etc. mas isso são de um valor tão insignificante que no orçamento de uma família de três pessoas, pode haver um aumento de dez centavos diários" ${ }^{40}$.

\footnotetext{
${ }^{38}$ Maria 1933: n. num.

${ }^{39}$ Maria 1936: n. num.

${ }^{40}$ Maria 1933: n. num.
} 
Em 1937, eventualmente aproveitando o sucesso de Rosa Maria, Branca Miraflor publicou Como de Almoça por pouco Dinheiro, obra composta por 28 menus diferentes, num total de 120 receitas $^{41}$. De novo não há receitas de sobremesas, sendo as de salgados apresentadas para cada dia, num total de quatro ou cinco. Não se indicaram os preços dos géneros. Neste caso, a redação das receitas foi bastante arcaica, não se fazendo a separação entre produtos e modo de preparação.

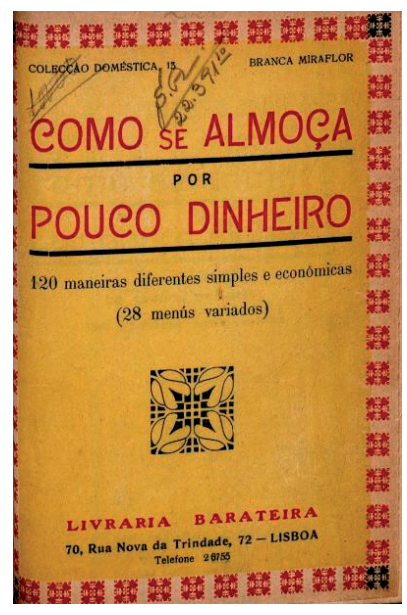

Fig. 7 - Capa da obra de Branca Miraflor.

Nas 28 ementas diferentes, Branca Miraflor começou sempre por apresentar uma sopa e terminou com uma salada, com exceção de sete refeições em que esta preparação deu lugar a alguma outra de legumes cozinhados. O destaque, em termos de peixe, foi para o bacalhau, presente em 14 dos 28 menus, isto é, em metade. A sardinha, igualmente um peixe barato ${ }^{42}$, ficou parcamente representada com apenas três receitas, a par de duas de caldeirada e, com um exemplo de cada, cação, carapau, congro, pescada, peixe do rio e sarda. No extremo oposto, uma receita de marisco, com lagosta, e outras com moluscos bivalves não particularmente dispendiosos: amêijoas e ostras.

\footnotetext{
${ }^{41}$ Miraflor 1937.

${ }^{42}$ Cf., a respeito dos consumos de bacalhau e de sardinha, Braga 2012: 889-893.
} 


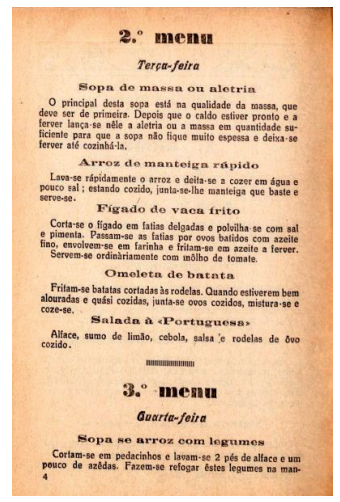

Fig. 8 - Página da obra de Branca Miraflor, na qual se apresenta o segundo menu completo e o início do terceiro.

No domínio da carne, predominaram as receitas de vísceras, em particular fígado, a par daquelas em que os enchidos constituíam o conduto. Encontrase ainda uma com bifes, e outras com pássaros, cabeça de porco, chispe e mãos de carneiro. Estão ausentes preparados com aves de caça e de criação, cabrito e coelho. Os ovos marcaram presença em oito preparados, três dos quais sob a forma de omelete. De resto, muitos preparados com arroz, alguns com batatas e uma presença significativa de legumes, alguns consumidos em verde, nas saladas, e de leguminosas.

Ou seja, tal como o título indica, estamos perante um conjunto de receitas bastante simples e económicas, destinadas a um público com baixos rendimentos e com poucas exigências a nível quer da preparação quer da apresentação dos pratos, a qual, aliás, nunca foi mencionada. Se a estas características juntarmos a ausência de sobremesas e a redação elementar das receitas, sem indicação das quantidades, dos tempos de preparação e de cocção e das porções, percebemos sem dificuldade estarmos perante um texto muito elementar destinado a assegurar o trivial dos menos abastados.

\section{EM Jeito de balanço}

Perante as três autoras, torna-se claro que sabemos muito mais sobre Estela Brandão do que sobre Rosa Maria ou Branca Miraflor. Em comum, tiveram preocupações no sentido de fornecer receitas que compilaram ao serviço de mulheres com menos conhecimentos e, eventualmente, com menos posses. Se as três autoras se inseriram no grupo de mulheres que, no século XX, se dedicou à publicação de receituários fáceis, acessíveis ${ }^{43}$, e sem

\footnotetext{
${ }^{43}$ Braga 2008: 117-141. Para outros espaços, cf. Capatti, Montanari 2002: 211.
} 
imagens, também é certo que visaram públicos diferenciados, isto é, mulheres com mais posses no caso de Estela Brandão e mulheres mais simples e com menos meios, no caso das restantes. Nos três casos, as autoras não foram cozinheiros criadores, artistas artesãos, monarcas absolutos da cozinha, dotados de espírito inventivo, como Leo Moulin definiu os maîtres ${ }^{44}$, foram pessoas que ficaram associadas à confeção dos pratos comuns e saborosos, que se repetiam sem perspetivas de inovação, o que, no âmbito dos seus propósitos, foi cabalmente conseguido, tal como aconteceu em outros espaços, caso da Itália fascista, em que não obstante as diferenças regionais, a frugalidade imperou, com exceção das refeições oficiais em que a etiqueta continuou a implicar sumptuosas refeições ${ }^{45}$.

Se tivéssemos que escolher uma única palavra para definir Estela Brandão não teríamos dúvida em optar por conservadora. Efetivamente, esta autora, que sempre se colocou no papel de quem tem conhecimentos para ensinar aos demais em várias áreas, como antes referimos, demonstrou, de forma sistemática, atitudes ao arrepio de qualquer tipo de novidade ou inovação quer ao nível das práticas sociais quer em relação aos próprios avanços científicos e tecnológicos. As crónicas que juntou sob o título Para vós, minhas Senhoras, em 1938, forneceram elementos inequívocos a esse respeito. Vejamos alguns exemplos. Numa, intitulada "Mulheres", criou uma tipologia: "há diversas categorias de mulheres: as que nasceram para mães, boas, indulgentes, piedosas; as que nasceram para amantes: tentadoras perigosas; e as que nasceram para flirtar, banais, vaidosas e também perigosas, trazendo atrás de si uma corte de admiradores" ${ }^{46}$. Escusado será salientar que só as primeiras eram dignas. Numa outra, sobre feminismo, definiu-o de forma peculiar, reafirmando o secular entendimento do papel da mulher: "consiste em preencher condignamente os vossos deveres de mulher, de mãe, de esposa, de filha ou de irmã. Quem sabe se qualquer de vós não desejou uma profissão masculina: advogada, médica, por exemplo [...] fazer do vosso lar um ninho acolhedor, sorridente e confortável, onde o marido e os filhos, se unam felizes em volta do lume vivificador e amigo [...] é honrar o vosso marido, é governar a casa com senso e economia, equilibrando o orçamento, evitando todas as despesas inúteis" ${ }^{47}$. Na crónica "Carpideiras" deteve-se nas questões familiares e religiosas: "É certo que as famílias numerosas têm maior despesa. Mas, nas famílias pequenas, quantas vezes se despende em luxo e em frivolidades o que os outros gastam no indispensável e útil [...] é preciso elevar a alma ao céu, com uma fé ardente em Deus, e um amor absoluto ao marido,

\footnotetext{
${ }^{44}$ Cf. Moulin 1989: 184 e as amplas considerações de Capatti, Montanari 2002: 293-303.

${ }^{45}$ Sobre esta matéria, cf. Mafai 2008: 85-89 e, em registo fotográfico, as imagens de mesas e de refeições de vários espaços italianos da época, no catálogo dirigido por Segredo 2015.

${ }^{46}$ Brandão 1938a: 45.

${ }^{47}$ Brandão 1938a: 207.
} 
aos filhos e à família. A religião é um sustentáculo poderoso para vencer todas as dificuldades, tornando-nos fortes para a luta, carinhosas e meigas, mesmo quando tenhamos razões para o contrário. Sendo assim, todos podem ser felizes, cooperando para o bem comum, da família, da sociedade e da pátria" ${ }^{48}$. Finalmente, em "O Poder da Vontade", não escamoteou a sua simpatia política: "há pessoas, porém, para quem o trabalho é uma distração. É nestes seres de eleição, que se encontram os génios, os grandes produtores cerebrais, os chefes, os autênticos homens de Estado, como Salazar e poucos mais" ${ }^{49}$.

Conservadora no que se refere ao entendimento do papel da mulher na sociedade, defensora dos ideais propagados pelo Estado Novo, sistematizados na máxima "Deus, Pátria e Família", apreciadora de Salazar e crítica de tudo o que representasse qualquer tipo de novidade, chegou ao ponto de escrever contra o cinema falado e o que entendeu ser o ritmo de vida moderno. Sobre o primeiro, designado animatógrafo, depois de fazer o elenco dos prejuízos que causava nas crianças, designadamente excitação e doenças várias, rematou: "não sei por que razão foi necessário dar voz às figuras que se movem na tela apenas em sombras" ${ }^{50}$. Sobre o segundo, as opiniões foram, no mínimo, bizarras: "a música, as notícias de sensação, chegam-nos pelas ondas hertzianas, por meio da telefonia sem fios, em segundos apenas. O correio já se faz por via aérea e há casais ultramodernos que escolhem o avião para a sua lua-de-mel. Tudo gira numa velocidade doida, atordoando-se, enervando-se, para alcançar os seus fins com a máxima rapidez" ${ }^{51}$.

Não obstante, uma crónica mostra alguma sensibilidade para os problemas relativos ao trabalho feminino e uma outra inesperada ousadia. $\mathrm{Na}$ primeira, intitulada "O Drama da Rua", pode ler-se: "há uma sociedade protectora dos animais, multam-se as pessoas que seguram os frangos pelas patas com a cabeça para baixo. Não há, porém, ninguém que interceda a favor da mulher, que evite que a sobrecarreguem demasiado, que não permita que puxem às carroças como animais, e que pelo menos lhes conceda um certo alívio e descanso nos últimos dois meses de gravidez" ${ }^{52}$. Se nesta se focou nas mulheres dos grupos mais desfavorecidos, tentando sensibilizar as leitoras para o problema, numa outra intitulada "Delicadeza Matrimonial”, o público-alvo foi o mesmo mas as ações seriam protagonizadas por mulheres menos desprotegidas socialmente. Nesta crónica pode ler-se: "aconselho a

${ }^{48}$ Brandão 1938a: 169-170.

${ }^{49}$ Brandão 1938a: 104.

${ }^{50}$ Brandão 1938a: 30. Sobre esta matéria, sabe-se que não foi caso único. Na Assembleia Nacional, concretamente em 1939, na segunda legislatura, o "animatógrafo" e os seus efeitos foram objeto de discussão, por parte da deputada e médica Domitila de Carvalho, cf. Braga 2016.

${ }^{51}$ Brandão 1938a: 123.

52 Brandão 1938a: 137. 
todas aquelas cujo marido tiver por hábito ler à mesa o jornal, levantar-se colocar no seu lugar o cão ou o gato, e terminar a refeição na cozinha, onde certamente a criada terá mais atenções para com ela" ${ }^{53}$. À ousadia, certamente mais para provocar do que para executar, seguiu-se o tom habitual: "a hora da refeição é uma hora sagrada, devendo pairar sempre a alegria e bom humor. Os antigos pagavam aos bobos para os divertirem enquanto comiam. Para que o alimento seja profícuo e salutar é preciso que um bem-estar moral, que uma disposição alegre, domine todos os espíritos" ${ }^{54}$.

Estela Brandão foi autora, no âmbito aqui em estudo, de um manual de etiqueta, de crónicas e uma de obra de culinária e de economia doméstica, enquanto Rosa Maria e Branca Miraflor se limitaram à publicação de obras de cozinha. Todos estes trabalhos, publicados durante o Estado Novo (19331974), serviram totalmente os ideais do regime, quer no que se refere aos entendimentos dos grandes valores, bem visíveis no caso de Estela Brandão, menos evidentes no caso das outras autoras, quer na prática quotidiana, situação semelhante à que se viveu em Itália, durante o fascismo (1922-1943) 55 . Poupar, reaproveitar ${ }^{56}$, obedecer, tratar do lar, educar as crianças e servir os maridos foram objetivos divulgados por diversos meios. Lembremos, em especial, que, por decreto de 8 de dezembro de 1937, o ministro da Educação Nacional, António Carneiro Pacheco, criou a Mocidade Portuguesa Feminina ${ }^{57}$, a qual teve um papel muito ativo nas escolas, junto das alunas e fora delas através da publicação de revistas, de acordo com as idades das meninas ${ }^{58}$. Em carta datada de 29 de março de 1949, consequentemente, após o período que aqui se tratou, Maria Manuela de Mendonça, então aluna do liceu lisboeta D. Filipa de Lencastre, escreveu: "eu agora tenho umas aulas muito engraçadas de culinária. Aprendemos a fazer uns pratos muito complicados, mas principalmente doces. São da Mocidade [Portuguesa Feminina] e tudo aquilo decorre numa brincadeira que sei lá! Somos seis de cada vez e depois de termos feito os pratos, vamos para a mesa, numa salinha contígua à cozinha, servimo-nos umas às outras, sob a vigilância da professora que por vezes também se associa à nossa refeiçãozinha" ${ }^{\text {"59 }}$. A análise dos cadernos das alunas permite ter uma ideia clara das opções seguidas nos liceus ${ }^{60}$.

${ }^{53}$ Brandão 1938a: 259.

${ }^{54}$ Brandão 1938a: 260-261.

${ }^{55}$ Helstosky 2004: 90-99. Agradeço ao Doutor António José Marques da Silva a indicação desta obra.

${ }^{56}$ Vaquinhas, Guimarães 2011: 194-221.

${ }^{57}$ Sobre a Mocidade Portuguesa Feminina, cf. Pimentel 2001 e Pimentel 2007.

58 Braga, Braga 2012: 201-226.

${ }^{59}$ Mendonça 2013: 75-76.

${ }^{60}$ Sobre esta matéria, cf. Braga 2008: 117-141. Para a Itália fascista, cf. Capatti, Montanari 2002: 302-303. 
Reflexo da época e ao serviço da época, as publicações destas autoras estiveram em consonância com a simplificação dietética, aliada à escassez dos géneros alimentares e às dificuldades económicas do período entre as duas guerras. A publicidade, que aqui não tratámos, encaminhou-se, como seria de esperar, exatamente no mesmo sentido ${ }^{61}$. Viviam-se tempos de alterações dos hábitos gastronómicos, com a diminuição de pratos por refeição, pondo fim à longa herança de sumptuosas refeições quotidianas entre os abastados. A II Guerra Mundial (1939-1945) consolidará estas realidades.

\section{Bibliografia}

\section{Fontes}

Brandão, E. (1937-1940, 2. a ed.), Arte e Economia, 3 vols, Livraria Simões Lopes, Porto. Brandão, E. (1938a), Para Vós, minhas senhoras. Conselhos de ordem moral e social, Livraria Simões Lopes, Porto.

Brandão, E. (1938b), Regras de Bem Viver na Sociedade, Livraria Simões Lopes, Porto.

Maria, R. (1933), Como se Almoça por 1\$00. 100 Almoços diferentes compostos por Carne, Peixe, Legumes, Ovos, Cereais, etc. orçamentados ao preço do Mercado, Empresa Literária Universal, Lisboa.

Maria, R. (1937, 3.a ed.), Como se Janta por 3\$00. 100 Jantares diferentes compostos por Sopa e um Prato de carne, Peixe, Legumes, Ovos, Cereais, etc., Empresa Litográfica, Lisboa.

Maria, R.(1959, 7. a ed.), A Cosinheira das Cosinheiras, Empresa Literária Universal, Lisboa.

Mendonça, M. M. de (2013), Memórias de uma Adolescente no Liceu D. Filipa de Lencastre (Dos Cadernos de Lisboa -1943 a 1950), Minerva, Coimbra.

Miraflor, B. (1937), Como se Almoça por Pouco Dinheiro. 120 Maneiras diferentes, simples e económicas (28 Menus Variados), Livraria Barateira, Lisboa.

\section{Estudos}

Braga, I. M. R. M. D. (2007), "Alimentação e Publicidade Alimentar na Revista $A B C$ (1920-1926)", in Turres Veteres IX - História da Alimentação Colibri, Lisboa: 215225.

Braga, I. M. R. M. D. (2008), “Culinária no Feminino: Os Primeiros Livros de Receitas Escritos por Portuguesas”, Caderno Espaço Feminino 19 (1): 117-141.

Braga, I. M. R. M. D. (2012), "Morue”, in J.-P. Poulain (dir.), Dictionnaire des Cultures Alimentaires PUF, Paris: 889-893.

Braga, I. M. R. M. D., Braga, P. D. (2004), “Civilidades. Porquê? Para quê? Para quem?”, in Maria Amália Vaz de Carvalho, Arte de Viver na Sociedade, Colares Editora, Sintra: 9-42.

\footnotetext{
${ }^{61}$ Sobre a publicidade no período entre as duas grandes guerras, cf. Braga 2007: 215-225.
} 
Braga, I. M. R. M. D., Braga, P. D. (2012), “A Mocidade Portuguesa Feminina e a Formação Culinária em Menina e Moça (1947-1962)”, Cadernos Pagu 39: 201226.

Braga, P. D. (2016), Mulheres Deputadas à Assembleia Nacional (1935-1974), Assembleia da República, Lisboa.

Capatti, A., Montanari, M. (2002), La Cuisine Italienne. Histoire d'une Culture, Seuil, [Paris].

Corner, P. (2015), Italia Fascista. Politica e Opinione Popolare sotto la Dittadura, Carocci Editore, Roma.

García, H. (2006), "El Turismo Político durante la Guerra Civil: Viajeros Británicos y Técnicas de Hospitalidad en la España Republicana (1936-1939)”, Ayer 64 (4): 287-308.

Gibert, M. (2009), A Segunda Guerra Mundial, tradução, Publicações D. Quixote, Lisboa. Helstosky, C. (2004), Garlic and Oil: Politics and Food in Italy, Berg, Oxford, New York.

Mafai, M. (2008, 7. a ed.), Pane Nero. Donne e Vita Quotidiana nella Seconda Guerra Mondiale, Ediesse, Roma.

Marques, A. H. de O. (1991a), “A Conjuntura”, in J. Serrão e A. H. de O. Marques (dir.), Nova História de Portugal, vol. 11, Presença, Lisboa, 709-717.

Marques, A. H. de O., (1991b), "A Alimentação”, in J. Serrão e A. H. de O. Marques (dir.), Nova História de Portugal, vol. 11, Presença, Lisboa, 617-626.

Martinez, P. S. (2001), A República Portuguesa $e$ as Relações Internacionais (1910-1926),Verbo, Lisboa.

Meneses, F. R. (2010, 2. ${ }^{\text {a }}$ ed.), Salazar. Uma Biografia Politica, tradução de Teresa Cabral, D. Quixote, Lisboa.

Moulin L. (1989), Les Liturgies de la Table: Une Histoire Culturelle du Manger et du Boire, Albin Michelle, [Paris].

Nunes, A. B., Brito, J. M. B. de (1992), "Política Económica, Industrialização e Crescimento", in J. Serrão e A. H. de O. Marques (dir.), Nova História de Portugal, vol. 12, Editorial Presença, Lisboa, 319-321.

Oliveira, A. L. de (1981), Dicionário de Mulheres Célebres, Lello \& Irmão Editores, Porto.

Parker, R. A. C., (1989), História da Segunda Guerra Mundial, tradução, Edições 70, Lisboa.

Pimentel I. F. (2001), História das Organizaçôes Femininas do Estado Novo, Temas e Debates, Lisboa.

Pimentel, I. F. (2007), Mocidade Portuguesa Feminina, A Esfera dos Livros, Lisboa.

Romero Samper, M. (2013), "Hambre y Retaguardia Protesta Social en la Madris de la Guerra Civil”, Estudios de Seguridad y Defensa 2: 159-190.

Rosas, F. (1994), "Sob os Ventos da Guerra: a primeira crise séria do Regime (19401949)" in J. Mattoso (dir.), História de Portugal, vol. 7, Editorial Estampa, Lisboa, 301-415.

Rosas, F. et all, "A guerra”, in F. Rosas e M. F. Rollo (coord.), História da Primeira República Portuguesa, Tinta-da-China, Lisboa, 245-406. 
Santos, M. T. (2005), "Estela Brandão" in Z. O. De Castro e J. Esteves (dir.), Dicionário no Feminino (séculos $X I X-X X)$, Livros Horizonte, Lisboa.

Segredo, A. M. (2015), Italiani a Tavola. Milleottocentosessenta - Millenovecentosessenta. Storia dell'Alimentazione della Cucina e della Tavola in Italia, Palombi Editori, Roma.

Silva, J. L. M. da (2008), Cozinha Modelo, Edusp, São Paulo.

Vaquinhas, I., Guimarães, M. A. P. (2011), "Economia Doméstica e Governo do Lar. Os Saberes Domésticos e as Funções da Dona de Casa”, in J. Mattoso (dir.) História da Vida Privada em Portugal, vol. 3, Círculo de Leitores, Temas \& Debates, Lisboa: 194-221.

Vieira, J. (2010), A Governanta. D. Maria, Companheira de Salazar, A Esfera dos Livros, Lisboa.

Visser, M. (1991), The Rituals of Dinner. The Origins, Evolution, Eccentricities and Meaning of Table Manners, Penguin Books, Londres. 